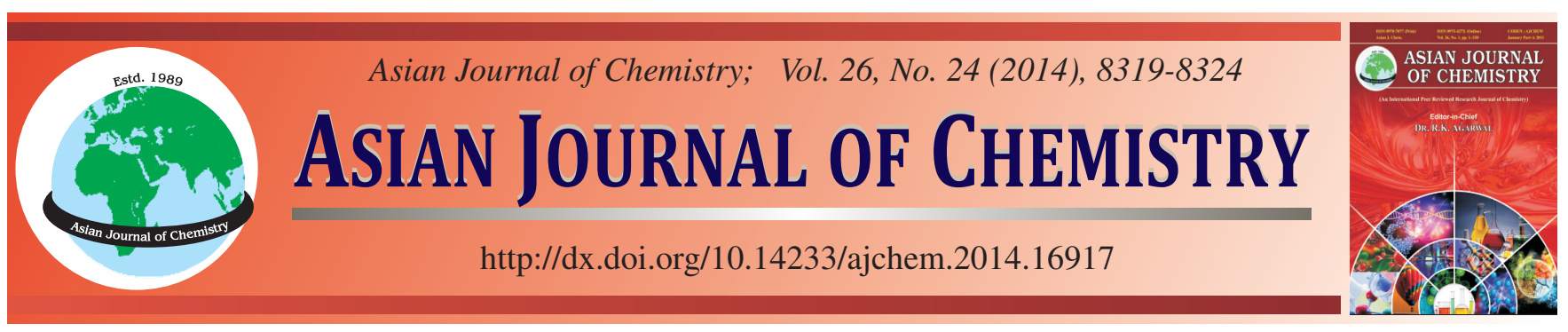

\title{
Synergistic Flame Retardancy of Aluminium Dipropyl-Phosphinate and Melamine Cyanurate in Polyamide-6
}

\author{
Wei He, Zhigang Yuan, Yujia Liu, Yuchong Wang and Linsheng Tang*
}

College of Chemical Engineering, Qingdao University of Science and Technology, Qingdao 266042, P.R. China

*Corresponding author: E-mail: linshengt62@163.com

Received: 24 December 2013; $\quad$ Accepted: 11 April 2014; $\quad$ Published online: 1 December 2014; $\quad$ AJC-16353

\begin{abstract}
The synergistic flame retardancy of aluminium dipropylphosphinate (ADPP) and melamine cyanurate (MCA) in polyamide 6 (PA6) was studied by the limiting oxygen index (LOI) measurement, the vertical burning test, the cone calorimeter test and the mechanism was also discussed by residural analysis. It was found that there was no obvious synergistic flame retardancy between aluminium dipropylphosphinate and melamine cyanurate in polyamide 6 . Compared with the flame-retarded polyamide 6 (FR-PA6) with aluminium dipropylphosphinate, the limiting oxygen index of the FR-PA6 with aluminium dipropylphosphinate/melamine cyanurate with appropriate weight ratios increased slightly, but vertical burning class, heat release rate (HRR), peak heat release rate (PHRR), mass loss rate (MLR) and total heat release (THR) were similar. Additionally, aluminium dipropylphosphinate/melamine cyanurate had a greater influence on the thermal stability of the composites than aluminium dipropylphosphinate and melamine cyanurate. The analysis of the residues obtained in cone calorimeter test showed that aluminium dipropylphosphinate played the role of flame retardancy by gaseous and condensed phase mechanisms. On one hand, aluminium dipropylphosphinate were decomposed into non-volatile aluminum phosphate and promoted the carbonization of polyamide 6 and the formed intumescent layer resulted in flame retardancy by the barrier effect on heat, air and decomposition products, on the other hand, it was decomposed into volatile phosphorus compounds which brought about flame retardancy by flame inhibition.
\end{abstract}

Keywords: Aluminium dipropylphosphinate, Melamine cyanurate, Synergistic flame retardancy, Polyamide 6.

\section{INTRODUCTION}

The alkylphosphinates developed by Clariant company (Germany) have some merits such as low toxicity and smoke density, high comparative tracking index (CCT), good thermal stability and efficient flame retardancy, especially used as a flame retardant for polyamides, polyesters and epoxy resin ${ }^{1-3}$. Although the dialkylphosphinate are only moderately efficient in nylons, they were found synergistic effect with some nitrogencontaining products like melamine ${ }^{4}$, melamine cyanurate ${ }^{5,6}$, melamine phosphate, or melamine polyphosphate ${ }^{7-9}$. For example, aluminium phosphinates in glass-fibre reinforced polyamide 6,6 is satisfactorily effective only on rather high loadings of $30 \mathrm{wt} . \%^{10}$. The phosphinate dosage can be reduced to about $10 \mathrm{wt} \%$ in the presence of melamine polyphosphate ${ }^{8}$. Despite of their increasing use, publications on the fireretardantcy mechanism of these phosphinate have been limited. The literature ${ }^{11}$ claimed that aluminium phosphinate in polyamide 6,6 acted mainly by flame inhibition. Melamine polyphosphate shows some fuel dilution and a significant barrier effect. Using a combination of aluminium diethylphosphinate and melamine polyphosphate results in some charring and a dominant barrier effect. These effects are improved in the presence of zinc borate due to the formation of boronaluminium phosphates instead of aluminium phosphates. The literature $^{12,13}$ also claimed that aluminium diethylphosphinate in glass-fiber reinforced poly(butylene-terephthalate) acted mainly by flame inhibition due to the release of the phosphinic acid in the gas phase. Additional charring influenced the flammability. The literature ${ }^{14}$ reported that the addition of organoclay increased the barrier effect of formed char in poly(ethyleneterephthalate). However, investigations about aluminium phosphinate and melamine polyphosphate as flame retardants in poly(methylmethacrylate) showed that the fire retardancy mechanism was mainly based on a condensed phase action $^{15}$.

So far, Clariant products and most investigations about the phosphinate flame retardants are based on diethylphosphinates, but they are more difficult to production due to very high pressure for ethylene liquefaction which results in storage and transportation difficulties. Taking into account that the propylene is easy liquefaction, so that its storage and transportation are more convenient and its price is low and its supply is more abundant than ethylene, we have developed aluminium 
dipropylphosphinate and commercialized in Shandong Brothers Science and Technology Co. Ltd., China and found that it has a good flame retardancy in polyamide 6 and an excellent synergistic effect with melamine ${ }^{4}$. However, it has no obvious synergistic flame retardancy with melamine cyanurate and melamine polyphosphate. In this work, the flame retardancy and its mechanisms of aluminium dipropylphosphinate in combination with melamine cyanurate in polyamide 6 were reported.

\section{EXPERIMENTAL}

Polyamide 6 was provided by Shijiazhuang Refining \& Chemical Co. China. The aluminium dipropylphosphinate and the melamine cyanurate were provided by Shandong Brothers Science and Technology Co. Ltd., China. The antioxidants of 1010 and 168 were provided by Beijing Jiyi chemical Co. Ltd., China. All materials used in this work were of technical grade and were used without further purification.

Preparation of flame-retarded samples: Polyamide 6, flame retardants, small amount of 1010 and 168 antioxidants were mixed at about $230{ }^{\circ} \mathrm{C}$ in a JS30A twin-screw extruder (Yantai City Qitong Machinery Co. Ltd., China.) with a rotor speed of 20-30 rpm. The well-mixed ingredients were cooled to ambient temperature and were mould-pressed into $100 \mathrm{~mm}$ $\times 100 \mathrm{~mm} \times 4 \mathrm{~mm}$ sheets at $220-230{ }^{\circ} \mathrm{C}$ under $5 \mathrm{MPa}$ by a 2G-10T press vulcanizer (Dongguan Zhenggong Mechanical and Electrical Equipment Technology Co., Ltd., China). The sheets were then cut into standard samples for flame retardant test.

Flammability tests: Limiting oxygen index was measured according to ASTM D 2863 with a JF-3 oxygen index meter (Jiangning Analytical Instrument Company, China). The specimens with a size of $100 \times 6.5 \times 4 \mathrm{~mm}^{3}$ were used.

The vertical burning test was carried out on a CZF-3 horizontal and vertical burning tester (Jiangning Analytical Instrument Company, China) with specimens with a size of $100 \times 13 \times 4 \mathrm{~mm}^{3}$ according to the UL 94 test standard.

The cone calorimeter test was conducted with a FTT standard cone calorimeter (FTT company, British ) in external heat fluxes of $50 \mathrm{~kW} / \mathrm{m}^{2}$ with specimens of $100 \mathrm{~mm} \times 100 \mathrm{~mm} \times$ $4 \mathrm{~mm}$ according to ISO5660.

Thermogravimetric analysis: Thermogravimetric exeriments were performed using a SDTQ600 thermogravimetric analyzer (TA company, United States) with a nitrogen flow of $50 \mathrm{~mL} / \mathrm{min}$. The samples (about $10 \mathrm{mg}$ ) were heated in $150 \mu \mathrm{L}$ alumina pans at a heating rate of $10{ }^{\circ} \mathrm{C} / \mathrm{min}$.
Morphology analysis of the residues: The morphology of the residue obtained in the cone calorimeter test was observed by a scanning electron microscopy (SEM, Model JSM-6700F Jeol, Japan).

Phosphorous content analysis: The content of phosphorous was measured by the method of gravimetric quimociac method $^{16}$.

\section{RESULTS AND DISCUSSION}

Limiting oxygen index and UL94 Classification: As the loading of flame retardants was $25 \mathrm{wt} \%$ based on the total weight of the composites, the effect of the formulation of the combinations of aluminium dipropylphosphinate and melamine cyanurate was investigated. As could be seen in Table-1, the weight ratios of aluminium dipropylphosphinate to melamine cyanurate had impact on the limiting oxygen index and vertical burning ratings of the FR-PA6. The limiting oxygen index of the FR-PA6 increased first and then decreased and vertical burning UL94 classification unchanged first and then decreased with the increase of the proportion of melamine cyanurate. The limiting oxygen index of the FR-PA6 alone with aluminium dipropylphosphinate could be up to $33.2 \%$ and the burning test could pass the demanding V-0 classification, while the limiting oxygen index of the FR- PA6 with melamine cyanurate was $27 \%$ and only the demanding V-2 classification could be reached, which revealed that the flame retardancy of aluminium dipropylphosphinate in polyamide 6 was much better than melamine cyanurate.

In order to further confirm the synergistic effect between aluminium dipropylphosphinate and melamine cyanurate, the influence of the loading of flame retardants on the limiting oxygen index and vertical burning classification was respectively investigated under the weight ratios of aluminium dipropylphosphinate to melamine cyanurate of 100:0, 85:15 and 0:100 and the results were shown in Table-2.

The limiting oxygen index of polyamide 6 was $22.5 \%$ and the burning test rating was failed. The limiting oxygen index of the FR-PA6 alone with aluminium dipropylphosphinate of 15 wt $\%$ could be up to $30.7 \%$, the demanding V-0 classification could be achieved, which indicated that aluminium dipropylphosphinate had a good flame retardancy in polyamide 6. As the weight ratios of aluminium dipropylphosphinate to melamine cyanurate was 85:15 and the loading of the combination was $15 \mathrm{wt} \%$, the limiting oxygen index could be up to $31.3 \%$ and $\mathrm{V}-0$ could also be achieved. The limiting oxygen index of the FR-PA6 alone with melamine cyanurate of $15 \mathrm{wt} \%$

TABLE-1

EFFECT OF THE WEIGHT RATIOS OF ALUMINIUM DIPROPYLPHOSPHINATE TO MELAMINE CYANURATE ON ITS FLAME RETARDANCY IN POLYAMIDE 6

\begin{tabular}{cccc}
\hline $\begin{array}{c}\text { w (Aluminium dipropylphosphinate) } \\
\text { w (melamine cyanurate) }\end{array}$ & Limiting oxygen index (\%) & UL-94 class & Combustion phenomenon \\
\hline $100: 0$ & 33.2 & V-0 & Difficult ignition, self-extinguishing, no drips \\
$90: 10$ & 36.3 & V-0 & Difficult ignition, self-extinguishing, no drips \\
$85: 15$ & 37.0 & V-0 & Difficult ignition, self-extinguishing, no drips \\
$75: 25$ & 35.5 & V-0 & Difficult ignition, self-extinguishing, no drips \\
$65: 35$ & 33.8 & V-0 & Difficult ignition, self-extinguishing, dripping \\
$55: 45$ & 32.6 & V-0 & Difficult ignition, self-extinguishing, dripping \\
$45: 55$ & 30.7 & V-1 & Gentle burning, self-extinguishing, no drips \\
$0: 100$ & 27.0 & V-2 & Slightly severe burning, dripping \\
\hline
\end{tabular}


TABLE-2

EFFECT OF THE LOADING OF FLAMERETARDANTS ON ITS FLAME RETARDANCY IN POLYAMIDE 6

\begin{tabular}{cccll}
\hline $\begin{array}{c}\text { w (Aluminium } \\
\text { dipropylphosphinate) } \\
\text { w (melamine cyanurate) }\end{array}$ & Loading (\%) & Limiting oxygen index (\%) & UL-94 class & \multicolumn{1}{c}{ Combustion phenomenon } \\
\hline & 0 & 22.5 & No rating & Severe burning, dripping \\
& 5 & 26.8 & No rating & Severe burning, dripping \\
$100: 0$ & 10 & 29.8 & V-1 & Gentle combustion, self-extinguishing, no drips \\
& 15 & 30.7 & V-0 & Difficult ignition, self-extinguishing, no drips \\
& 20 & 32.2 & V-0 & Difficult ignition, self-extinguishing, no drips \\
& 25 & 33.2 & V-0 & Difficult ignition, self-extinguishing, no drips \\
\hline & 5 & 28.2 & No rating & Severe burning, dripping \\
& 10 & 30.1 & V-1 & Gentle burning, self-extinguishing, no drips \\
& 15 & 31.3 & V-0 & Difficult ignition, self-extinguishing, no drips \\
& 20 & 33.3 & V-0 & Difficult ignition, self-extinguishing, no drips \\
& 25 & 37.0 & V-0 & Difficult ignition, self-extinguishing, no drips \\
\hline \multirow{3}{*}{$0: 15$} & 5 & 23.1 & No rating & Severe burning, dripping \\
& 10 & 24.5 & No rating & Severe burning, dripping \\
& 15 & 25.4 & No rating & Severe burning, dripping \\
& 20 & 26.6 & No rating & Severe burning, dripping \\
& 25 & 27.0 & V-2 & Slightly severe burning, dripping \\
\hline
\end{tabular}

was only $25.4 \%$ and the burning test rating was failed. Thus it could be found that there was not obvious synergistic flame retardancy between aluminium dipropylphosphinate and melamine cyanurate, which wasn't consistent with that reported in literature ${ }^{5,6}$. This might be due to different phosphinates and polymers used. Fortunately, the combination of aluminium dipropylphosphinate and melamine cyanurate was more economical because melamine cyanurate was of low-cost than aluminium dipropylphosphinate.

Cone calorimetry analysis: The heat release rate (HRR), mass loss rate (MLR), total heat release (THR), mass curve of polyamide 6 and the FR-PA6 were, respectively illustrated in Figs. 1 to 4 and the important cone calorimetry data were tabulated in Table-3. As observed, the fire behaviour of polyamide 6 was similar with the FR-PA6 with 25 wt \% melamine cyanurate, both of them burned fastly after ignition, heat release rate, mass loss rate and total heat release increased rapidly, while the mass decreased rapidly, but the mass of the later decreased more rapidly and the curves of heat release rate and mass loss rate were characterized by a sharp peak. However, peak heat release rate (PHRR), total heat release, average heat release rate (MHRR), peak effective heat of combustion (PEHC), average effective heat of combustion (MEHC) were obviously reduced by adding melamine cyanurate. The above results showed that polyamide 6 was flammable and melamine cyanurate had a poor fire retardancy in polyamide 6 . The heat release rate, mass loss rate and total heat release of the FR-PA6 alone with $25 \mathrm{wt} \%$ aluminium dipropylphosphinate increased slowly after ignition, the mass decreased slowly, the heat release rate maintained at 200-469 $\mathrm{kw} / \mathrm{m}^{2}$ during the burning of $115-445 \mathrm{~s}$ and the curves of heat release rate were characterized by a wider peak, the peak heat release rate and average heat release rate were markedly reduced and the time for peak heat release rate and complete combustion increased significantly, which suggested slower combustion, in other words, aluminium dipropylphosphinate had a good fire retardancy, but the total heat release and average effective heat of combustion increased slightly. The fire

\begin{tabular}{ccccc}
\multicolumn{5}{c}{ TABLE-3 } \\
CONE CALORIMETRY DATA FOR \\
POLYAMIDE 6 AND FR- PA6 \\
\hline Term & $\begin{array}{c}\text { Polyamide } \\
\text { MCA/ }\end{array}$ & ADPP/ & ADPP/MCA \\
& 6 & PA6 & PA6 & /PA6 \\
\hline THR $\left(\mathrm{MJ} / \mathrm{m}^{2}\right)$ & 122.01 & 87.29 & 127.25 & 130.01 \\
PHRR $\left(\mathrm{Kw} / \mathrm{m}^{2}\right)$ & 1187.00 & 1013.31 & 469.00 & 403.25 \\
PHRR, time $(\mathrm{s})$ & 185 & 145 & 310 & 280 \\
MHRR $\left(\mathrm{Kw} / \mathrm{m}^{2}\right)$ & 372.06 & 239.24 & 221.32 & 220.54 \\
PEHC $(\mathrm{MJ} / \mathrm{kg})$ & 80 & 67.65 & 80 & 78.12 \\
MEHC $((\mathrm{MJ} / \mathrm{kg})$ & 21.54 & 14.19 & 24.35 & 28.26 \\
MMLR $(\mathrm{g} / \mathrm{s})$ & 0.10 & 0.07 & 0.07 & 0.07 \\
TTI $(\mathrm{s})$ & 75 & 75 & 80 & 80 \\
Combustion time $(\mathrm{s})$ & 380 & 360 & 570 & 585 \\
\hline
\end{tabular}

THR: Total heat release; PHRR: Peak heat release rate; MHRR: Average heat release rate; PEHC: Peak effective heat of combustion; MEHC: Average effective heat of combustion; MMLR: Average mass loss rate; TTI: Time to ignition

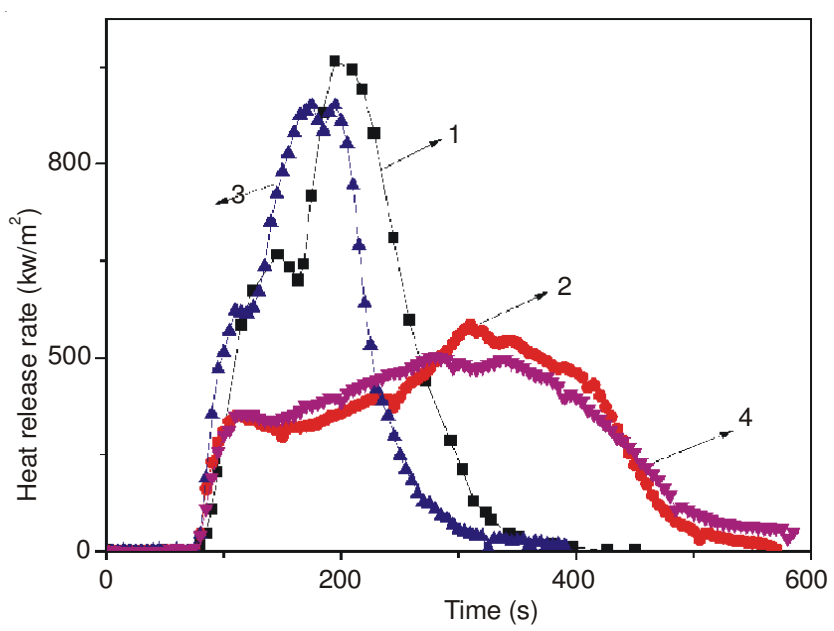

Fig. 1. Heat release rate curves of polyamide 6 and flame-retarded polyamide $6: 1$. polyamide $6 ; 2$. flame retarded polyamide 6 with 25 wt $\%$ of aluminium dipropylphosphinate; 3 . flame retarded polyamide 6 with $25 \mathrm{wt} \%$ of melamine cyanurate; 4 . flame retarded polyamide 6 with 25 wt \% of aluminium dipropylphosphinate/ melamine cyanurate (the weight ratio of aluminium dipropylphosphinate and melamine cyanurate being $85 / 15$ ) 


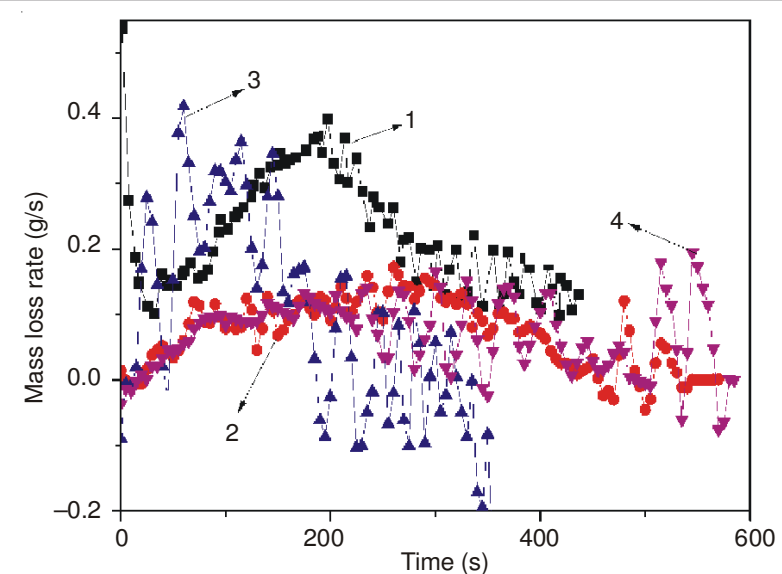

Fig. 2. Mass loss rate curves of polyamide 6 and flame-retarded polyamide 6 : 1. polyamide $6 ; 2$. flame retarded polyamide 6 with $25 \mathrm{wt} \%$ of aluminium dipropylphosphinate; 3 . flame retarded polyamide 6 with 25 wt $\%$ of melamine cyanurate; 4 . flame retarded polyamide 6 with 25 wt $\%$ of aluminium dipropylphosphinate/melamine cyanurate (the weight ratio of aluminium dipropylphosphinate and melamine cyanurate being $85 / 15$ )

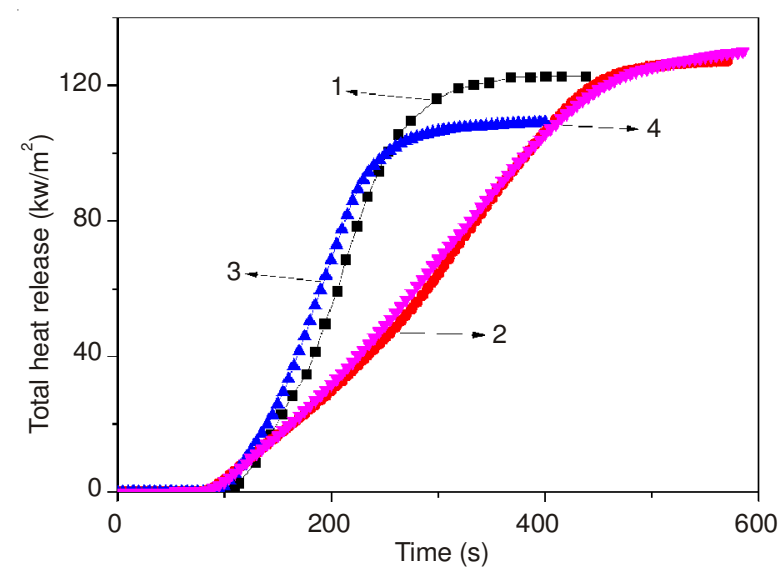

Fig. 3. Total heat release curves of polyamide 6 and flame-retarded polyamide 6: 1 . polyamide $6 ; 2$. flame retarded polyamide 6 with 25 wt $\%$ of aluminium dipropylphosphinate; 3 . flame retarded polyamide 6 with $25 \mathrm{wt} \%$ of melamine cyanurate; 4 . flame retarded polyamide 6 with $25 \mathrm{wtm} \%$ of aluminium dipropylphosphinate/ melamine cyanurate (the weight ratio of aluminium dipropylphosphinate and melamine cyanurate being $85 / 15$ )

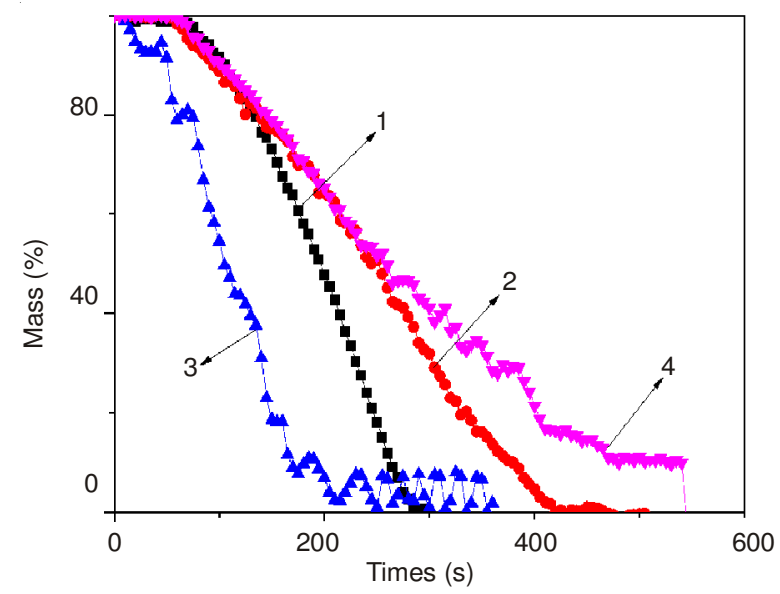

Fig. 4. Mass curves of polyamide 6 and flame-retarded polyamide 6 : 1. polyamide $6 ; 2$. flame retarded polyamide 6 with $25 \mathrm{wt} \%$ of aluminium dipropylphosphinate; 3 . flame retarded polyamide 6 with 25 wt $\%$ of melamine cyanurate; 4 . flame retarded polyamide 6 with 25 wt $\%$ of aluminium dipropylphosphinate/melamine cyanurate (the weight ratio of aluminium dipropylphosphinate and melamine cyanurate being $85 / 15$ ) behaviour of the FR-PA6 with aluminium dipropylphosphinate/ melamine cyanurate was similar with the FR-PA6 with aluminium dipropylphosphinate, which further confirmed that there wasn't obvious synergistic flame retardancy between aluminium dipropylphosphinate and melamine cyanurate in polyamide 6 .

Thermogravimetric analysis: Thermogravimetric results of flame retardants and FR-PA6 were presented in Figs. 5 and 6 and Table-4. As could be seen in Fig. 5 and Table-4, the initial thermal decomposition temperature $\left(\mathrm{T}_{\mathrm{i}-2 \mathrm{wt}} \%\right.$, the temperature at $2 \mathrm{wt} \%$ mass loss) of aluminium dipropylphosphinate and melamine cyanurate were 315.8 and $321{ }^{\circ} \mathrm{C}$, respectively and subsequently the mass loss of aluminium dipropylphosphinate was smaller than melamine cyanurate under the same temperature. The complete pyrolysis temperature of aluminium dipropylphosphinate and melamine cyanurate were 500 and $400{ }^{\circ} \mathrm{C}$, respectively and their resulting residues under the above temperature was about 14 and $0 \mathrm{wt} \%$, respectively. The $\mathrm{T}_{\mathrm{i}-2 \mathrm{wt}} \%$ of the combination (aluminium dipropylphosphinate/ melamine cyanurate) consisted of $85 \mathrm{wt} \%$ aluminium dipropyl phosphinate and $15 \mathrm{wt} \%$ melamine cyanurate was $321{ }^{\circ} \mathrm{C}$ which was higher than aluminium dipropylphosphinate and melamine cyanurate and the decomposition temperature at

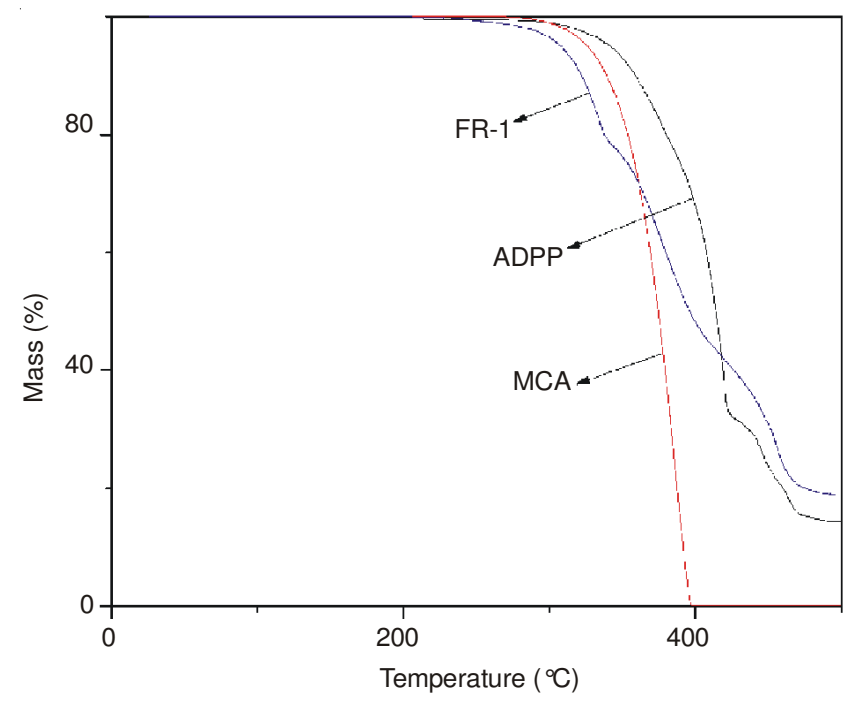

Fig. 5. TG of flame retardants

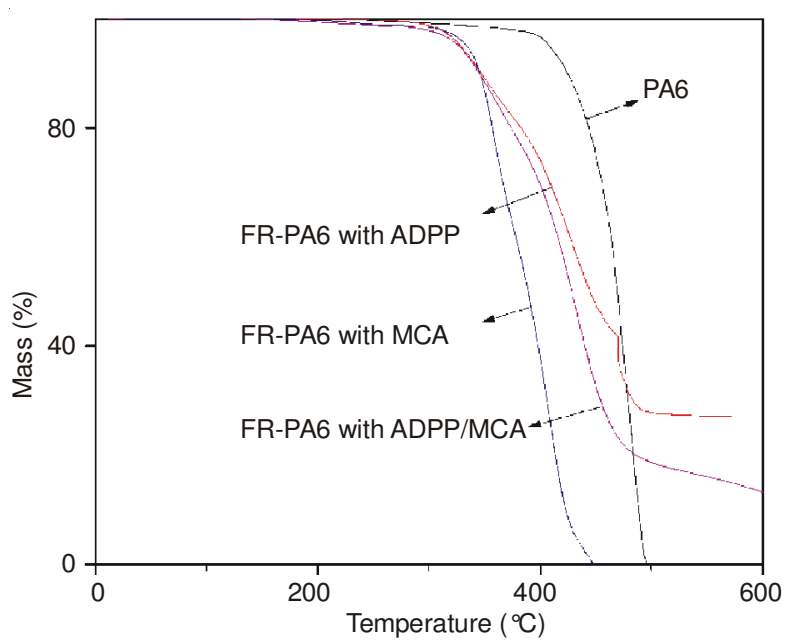

Fig. 6. TG of the flame retarded polyamide 6 with flame retardants 


\begin{tabular}{|c|c|c|c|c|}
\hline \multicolumn{5}{|c|}{$\begin{array}{c}\text { TABLE-4 } \\
\text { THEMOGRAVIMETRIC RESULTS }\end{array}$} \\
\hline Materials & $\mathrm{T}_{\mathrm{i}-2 \mathrm{w} t \%}\left({ }^{\circ} \mathrm{C}\right)$ & $\mathrm{T}_{\mathrm{i}-5 \mathrm{wt} \%}\left({ }^{\circ} \mathrm{C}\right)$ & $\mathrm{T}_{\mathrm{i}-10 \mathrm{w} \%}\left({ }^{\circ} \mathrm{C}\right)$ & Residue at $600{ }^{\circ} \mathrm{C}$ (wt. \%) \\
\hline PA6 & 333.6 & 386.1 & 402.6 & 0.2 \\
\hline ADPP & 315.8 & 342.3 & 358.8 & $14.5\left(500^{\circ} \mathrm{C}\right)$ \\
\hline MCA & 321.0 & 334.6 & 350.1 & $0.2\left(500^{\circ} \mathrm{C}\right)$ \\
\hline $85 \%$ ADPP/ $15 \%$ MCA & 321.0 & 334.6 & 350.1 & $18.9\left(500^{\circ} \mathrm{C}\right)$ \\
\hline Flame retarded PA6 with 25 wt $\%$ ADPP & 309.7 & 328.4 & 346.9 & 27.1 \\
\hline Flame retarded PA6 with 25 wt \% MCA & 308.9 & 333.9 & 345.8 & 0.2 \\
\hline Flame retarded PA6 with 25 wt \% ADPP/MCA* & 293.8 & 326.5 & 345.2 & 13.2 \\
\hline
\end{tabular}

at 5 and $10 \mathrm{wt} \%$ mass loss $\left(\mathrm{T}_{\mathrm{i}-5 \mathrm{wt}} \%\right.$ and $\left.\mathrm{T}_{\mathrm{i}-10 \mathrm{wt} \%}\right)$ were, respectively 334.6 and $350.1{ }^{\circ} \mathrm{C}$ which was between aluminium dipropylphosphinate and melamine cyanurate.

As could be seen in Fig. 6 and Table-4, polyamide 6 was initially decomposed in $333.6^{\circ} \mathrm{C}\left(\mathrm{T}_{\mathrm{i}-2 \mathrm{wt} \%}\right)$, rapidly over $402.6{ }^{\circ} \mathrm{C}$ and almost completely in $500{ }^{\circ} \mathrm{C}$ without any residue, which meant that polyamide 6 was extremely difficult to be carbonized. The FR-PA6 with 25 wt $\%$ aluminium dipropylphosphinate was initially decomposed in $309.7^{\circ} \mathrm{C}$ and the $\mathrm{T}_{\mathrm{i}-5 \mathrm{wt}} \%$ and $\mathrm{T}_{\mathrm{i}-10 \mathrm{wt}} \%$ were, 328.4 and $346.9^{\circ} \mathrm{C}$, respectively, obviously lower than polyamide 6 , which suggested that the addition of aluminium dipropylphosphinate cut down the thermal stability of polyamide 6 . The $27 \%$ residual rate in $600{ }^{\circ} \mathrm{C}$ indicated improved charring of polyamide 6 by adding aluminium dipropylphosphinate. The $\mathrm{T}_{\mathrm{i}-2 \mathrm{wt} \%}, \mathrm{~T}_{\mathrm{i}-5 \mathrm{w} t}$ and $\mathrm{T}_{\mathrm{i}-10 \mathrm{w} t}$ of the FRPA6 with $25 \mathrm{wt} \%$ of melamine cyanurate were $308.9,333.9$ and $345.8^{\circ} \mathrm{C}$, respectively, obviously lower than that of the FR-PA6 with 25 wt $\%$ aluminium dipropylphosphinate, which suggested that the addition of melamine cyanurate more seriously reduced the thermal stability of polyamide 6 than aluminium dipropylphosphinate. The $\mathrm{T}_{\mathrm{i}-2 \mathrm{wt} \%}, \mathrm{~T}_{\mathrm{i}-5 \mathrm{wt} \%}$ and $\mathrm{T}_{\mathrm{i}-10 \mathrm{w} t} \%$ of the FR-PA6 with $25 \mathrm{wt} \%$ aluminium dipropylphosphinate/ melamine cyanurate were $293.8,326.5$ and $345.2^{\circ} \mathrm{C}$, respectively, which was lower than polyamide 6 and FR-PA6 with aluminium dipropylphosphinate or melamine cyanurate, which indicated that aluminium dipropylphosphinate/melamine cyanurate had greater influence on the thermal stability of the materials. The $13 \%$ resulting residues in $600{ }^{\circ} \mathrm{C}$ was much more than the additive value of $5 \%$, which revealed improved charring of polyamide 6 by adding aluminium dipropylphosphinate/melamine cyanurate.

Fire retardancy mechanism: The flame retardancy mechanism of aluminium dipropylphosphinate and aluminium dipropylphosphinate/melamine cyanurate in polyamide 6 was discussed by the analysis of the residues obtained in cone calorimeter test. As could be seen in the photos of residues shown in Fig. 7, the residue of polyamide 6 and the FR-PA6 with melamine cyanurate did not form the intumescent char layer and their residual rate were respectively 0.5 and $0.8 \mathrm{wt} \%$, while the FR-PA6 with aluminium dipropylphosphinate and aluminium dipropylphosphinate/melamine cyanurate formed the intumescent char layer and their residual rate were respectively 3.5 and $2.9 \mathrm{wt} \%$, which indicated that the charring of the latter two was better than that of the former two.

The SEM pictures of the residues presented in Fig. 8 showed that the smooth and dense layers were formed after the combustion of the FR-PA6 with aluminium dipropylphosphinate and aluminium dipropylphosphinate/melamine cyanurate, which
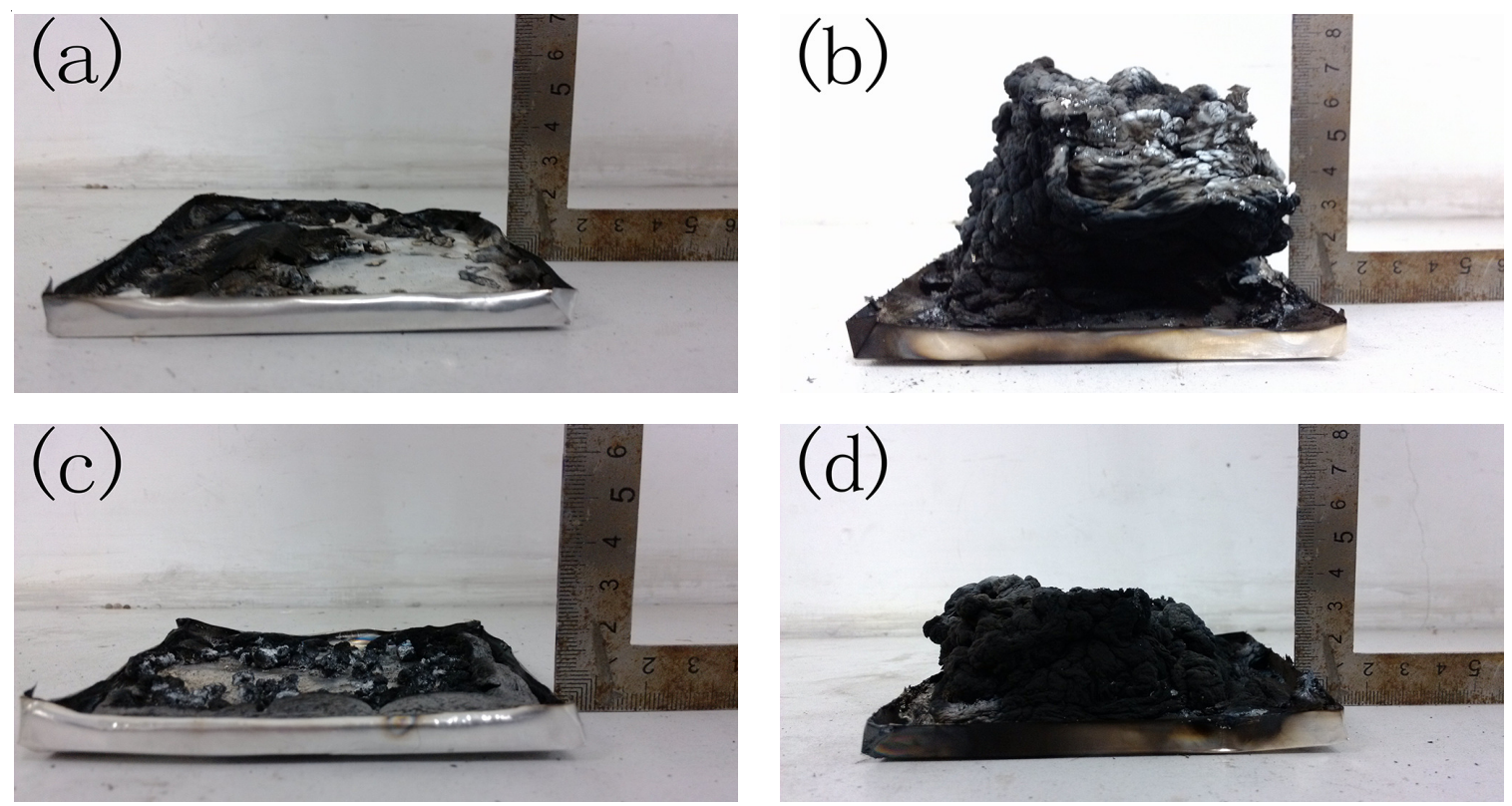

Fig. 7. Photos of the residue obtained in the cone calorimeter test: (a) polyamide 6; (b) flame retarded polyamide 6 with 25 wt $\%$ of aluminium dipropylphosphinate; (c) flame retarded polyamide 6 with $25 \mathrm{wt} \%$ of melamine cyanurate; (d) flame retarded polyamide 6 with 25 wt \% of 85 wt $\%$ aluminium dipropylphosphinate/15\% wt melamine cyanurate 


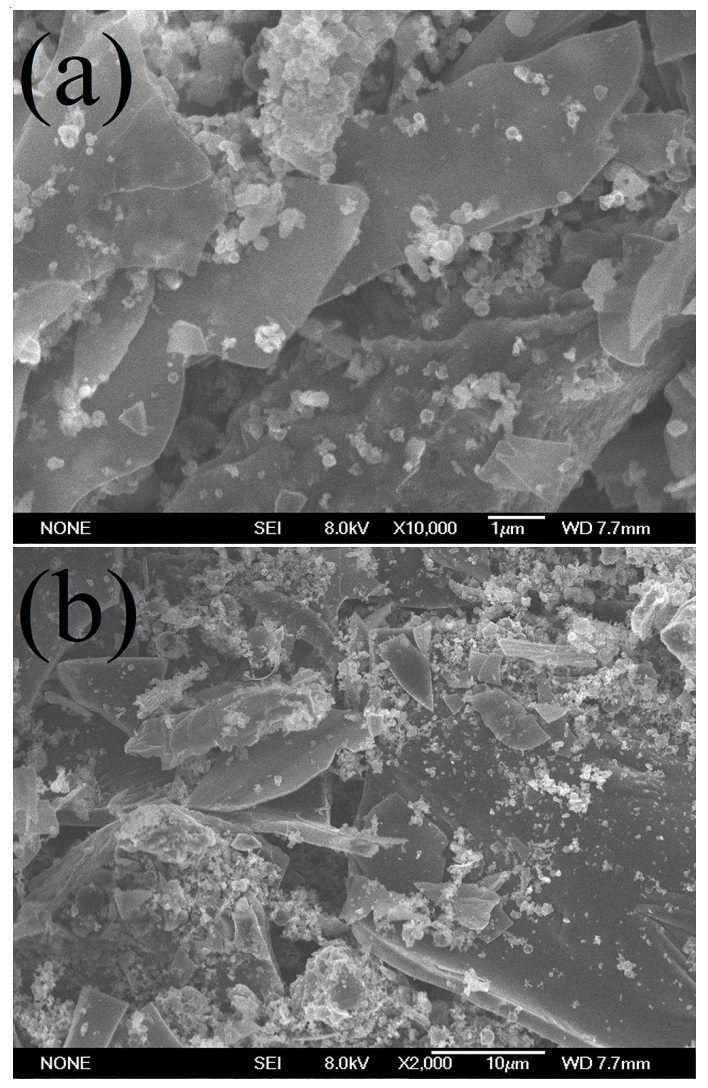

Fig. 8. SEM pictures of the residue obtained in the cone calorimeter: (a) flame retarded polyamide 6 with 25 wt $\%$ of aluminium dipropylphosphinate; (b) flame retarded polyamide 6 with 25 wt $\%$ of 85 wt $\%$ aluminium dipropylphosphinate/15 wt $\%$ melamine cyanurate

brought about the flame retardancy by the barrier effect on heat, air and decomposition products ${ }^{12}$.

The phosphorus content in the residues of the FR-PA6 with aluminium dipropylphosphinate and aluminium dipropylphosphinate/melamine cyanurate was respectively 18.5 and $19.1 \%$ and all the phosphorus residual rate of the both was only $13.4 \%$, which implied that most of the decomposition products of aluminium dipropylphosphinate were vaporized to gaseous phase in the process of combustion. The above analysis revealed that aluminium dipropylphosphinate and aluminium dipropylphosphinate/melamine cyanurate played the flame retardancy by gaseous and condensed phase mechanisms, on the one hand, they were decomposed into nonvolatile aluminum phosphate ${ }^{12}$ and promoted the carbonization of polyamide 6 and the formed intumescent layer resulted in flame retardancy by the barrier effect on heat, air and decomposition products ${ }^{12}$, on the other hand, it was decomposed into volatile phosphorus compounds such as dipropylphosphinic acid which brought about flame retardancy by flame inhibition $^{12-14}$. Melamine cyanurate was decomposed into volatile compounds such as $\mathrm{CO}_{2}$ and $\mathrm{NH}_{3}$ which showed some fuel dilution effects ${ }^{13,14}$.

\section{Conclusion}

There was not obvious synergistic flame retardancy between aluminium dipropylphosphinate and melamine cyanurate in polyamide 6. Compared with the FR-PA6 with aluminium dipropylphosphinate, the limiting oxygen index of FR-PA6 with aluminium dipropylphosphinate/melamine cyanurate with the appropriate weight ratios increased slightly, but vertical burning rating, heat release rate, peak heat release rate, average heat release rate, mass loss rate and total heat release were similar. For example, the limiting oxygen index of the FRPA6 alone with 15 wt \% aluminium dipropylphosphinate was $30.7 \%$, while the limiting oxygen index of the FR-PA6 with 15 wt \% aluminium dipropylphosphinate/melamine cyanurate could be up to $31.3 \%$ and all the both could pass the demanding $\mathrm{V}-0$ classification of the burning test. In addition, aluminium dipropylphosphinate/melamine cyanurate had greater influence on the thermal stability of the composites than aluminium dipropylphosphinate and melamine cyanurate. Fortunately, the combination of aluminium dipropylphosphinate and melamine cyanurate was more economical because melamine cyanurate was much low-cost than aluminium dipropylphosphinate. The analysis of the residues obtained in cone calorimeter test showed that aluminium dipropylphosphinate and aluminium dipropylphosphinate/melamine cyanurate played the role of flame retardancy by gaseous and condensed phase mechanisms.

\section{ACKNOWLEDGEMENTS}

This work is financially supported by Shandong Provincial Natural Science Foundation, Grant No. ZR2012BM017.

\section{REFERENCES}

1. S. Hörold, B. Naß, O. Schacker and W. Wanzke, A New Generation of Flame Retarded Polyamides Based on Phosphinates, Proceedings of Flame Retardant, Interscience Publisher, London (2004).

2. S. Hoerold, Flame Retarding Thermosetting Compositions, US Patent 6,420,459 (2002).

3. J.R. Campbell, B. Duffy, J.R. Rude, P. Susarla, M.A. Vallance, G.W. Yaeger and K.P. Zarnoch, Flame-Retardant Thermosetting Composition and Method, WO2005/033179 (2005).

4. L.S. Tang, Z.G. Yuan, L. Xu, X. Li and Y.Z. Ge, Adv. Mater. Sci. Eng., Article ID 960914 (2013).

5. E. Jenewein, H.-J. Kleiner, W. Wanzke and W. Budzinsky, Synergistic Flame Protection Agent Combination for Rheromoplastic Polymers, US Patent 6,365071 (2002).

6. M. Klatt, B. Leutner, M. Nam and H. Fisch, Flame-Retardant Polyester Molding Compositions Containing Flame-Retardant Nitrogen Compounds and Diphosphinates, US Patent 6,503,969 (2003).

7. E. Schlosser, B. Nass and W. Wanzke, Flame-Retardant Combination, US Patent 6,255,371 (2001).

8. B. Nass and W. Wanzke, Synergistic Flameproofing Composition for Polymers, US Patent 6,207,736 (2001).

9. L.S. Tang, Q.M. Liu, Y.Q. Li and S. Zhang, China Plastics Ind., 39, 110 (2011).

10. H.-J. Kleiner, W. Budzinsky and G. Kirsch, Low-Fammability Polyamide Molding Materials, US Patent 5,773556 (1998).

11. U. Braun, B. Schartel, M.A. Fichera and C. Jäger, Polym. Degrad. Stab., 92, 1528 (2007).

12. U. Braun and B. Schartel, Macromol. Mater. Eng., 293, 206 (2008).

13. U. Braun, H. Bahr, H. Sturm and B. Schartel, Polym. Adv. Technol., 19, 680 (2008).

14. M. Dogan, S. Erdogan and E. Bayramli, J. Therm. Anal. Calorim., 112, 871 (2013).

15. A. Laachachi, M. Cochez, E. Leroy, M. Ferriol and J.M. Lopez-Cuesta, Polym. Degrad. Stab., 92, 61 (2007).

16. Association of Official Analytical Chemists, Official Methods of Analysis, edn. 10, p. 12 (1965). 